
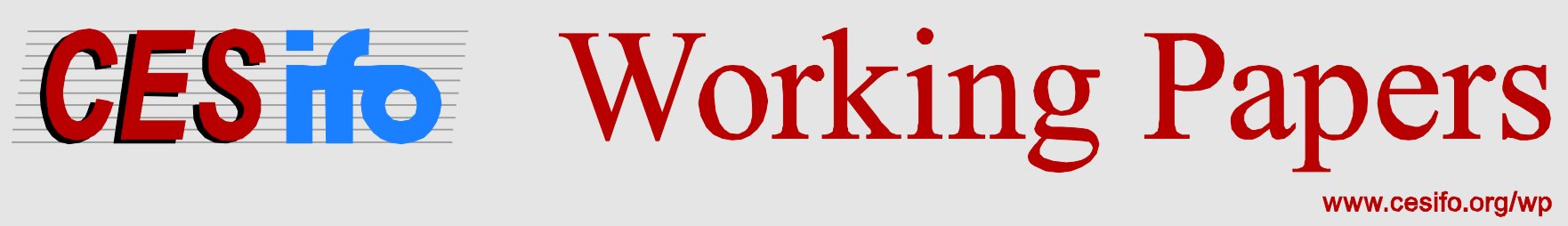

\title{
Assessing Market (Dis)Integration in Early Modern China and Europe
}

\author{
Daniel Bernhofen \\ Markus Eberhardt \\ Jianan Li \\ Stephen Morgan
}

\section{CESIFO WORKING PAPER NO. 5580 \\ CATEGORY 12: EMPIRICAL AND THEORETICAL METHODS \\ OCTOBER 2015}

An electronic version of the paper may be downloaded

- from the SSRN website:

- from the RePEc website:

- from the CESifo website:

WwW.SSRN.com

www.RePEc.org

www.CESifo-group.org/wp

\section{CESifo}




\title{
Assessing Market (Dis)Integration in Early Modern China and Europe
}

\begin{abstract}
This paper challenges established claims of comparable degrees of market integration in Europe and China on the eve of industrialization. Our empirical strategy focuses on the dynamics of price convergence and accounts for general equilibrium effects arising from common shocks and network effects. Using monthly grain prices for 1740-1820 our analysis uncovers a secular process of market disintegration in 221 prefectures of Qing China. Comparing our results with those for grain price panels from Western Europe we conclude that in terms of market integration the Great Divergence was well under way decades before the start of the 19th century.
\end{abstract}

JEL-Codes: F150, N750, L110, C230, O100.

Keywords: comparison of Chinese and western European market integration, price convergence, common factor model, cross-section dependence.

Daniel M. Bernhofen* School of International Service American University 4400 Massachusetts Ave NW USA - Washington, DC 20016-8071 dbernhof@american.edu

Jianan $\mathrm{Li}$

School of Economics

Xiamen University

Xiamen / PR China

jianan.li@xmu.edu.cn
Markus Eberhardt

School of Economics

University of Nottingham

Nottingham / United Kingdom

markus.eberhardt@nottingham.ac.uk

Stephen Morgan

University of Nottingham

Ningbo / PR China

stephen.morgan@nottingham.edu.cn

*corresponding author

October 12, 2015 


\section{Introduction}

One of the seminal questions in world and Chinese economic history is why China, in contrast to Western Europe, failed to industrialize during the $18^{\text {th }}$ and $19^{\text {th }}$ centuries: the question about the causes for the 'Great Divergence." Social and economic historians have tried to tackle this question by identifying necessary conditions for industrialization. One prominent condition has been the degree of market integration of an agricultural economy, with the argument that integrated markets generate static and dynamic gains from specialization and trade which then facilitate the transition from an agricultural to an industrial economy.

A long-held view has maintained that Western Europe was characterized by integrated markets, which had taken root because of statesupported property rights institutions, while in China markets were underdeveloped despite the unified political system created by a dynastic empire. This view has been challenged by a revisionist body of scholarship, most notably Wong (1997), Frank (1998) and Pomeranz (2000), who have claimed that early modern China was not only on par with Western Europe, but even conjectured that "eighteenth-century China... came closer to resembling the neoclassical ideal of a market economy than did western Europe" (Pomeranz, 2000: 70).

Recent econometric evidence by Shiue and Keller (2007) provided empirical support for the revisionist view that the level of market integration in Southern China was quite comparable to that in Western Europe at the dawn of the Industrial Revolution. The continuing rise in prominence of Shiue and Keller's (2007) findings has helped transform what was once a revisionist view into a now conventional view that differences in market integration can be ruled out as an explanation for the Great Divergence.

\footnotetext{
${ }^{1}$ There is now a large literature on the Great Divergence, but a seminal work is Pomeranz (2000) and important critiques are Brenner and Isett (2002) and Huang (2002). For an extensive recent survey see Vries (2015).
} 
This paper revisits the question regarding the degree of market integration in early modern China and Europe and challenges the conclusions of Shiue and Keller (2007) and earlier studies (Wang, 1989, 1992; Wang and Chen, 2002). While Shiue and Keller's (2007) empirical analysis is based on cross-continental comparisons of averaged cointegration test statistics for market pairs in China and Europe, our approach assesses the dynamic evolution of market integration while taking account of the general equilibrium effects arising from common shocks and network effects. We apply novel econometric techniques to rich panel data on grain prices from China and Europe for the $18^{\text {th }}$ and early $19^{\text {th }}$ centuries. Our dynamic analysis of market integration confirms historical narratives that market integration in the South of China was more advanced than in the North. ${ }^{2}$ Our estimates further uncover a prolonged process of market disintegration for the Chinese empire leading to uniformly lower degrees of market integration relative to Western Europe on the eve of Western Industrialization. We demonstrate that the combination of addressing general equilibrium effects and examining subperiods creates the divergence in our results from Shiue and Keller (2007).

The revealed weakening in integration over time in both regions lends support to existing arguments that have emphasised the segmentation of China's regional economies (Skinner, 1977a), the presence of vibrant local markets without there being integration between regions (Rawski, 1972), and environmental-technological constraints arising from the fundamental character of water control and transport systems in the absence of technological break-through and against a background of weakening (fiscal) capacity of the state (Elvin, 1973, 2004; Perkins, 1969; Rawski, 1972; Skinner, 1977; Sng, 2014).

\footnotetext{
${ }^{2}$ This supremacy is widely recognized in the literature, with its origins attributed largely "to the relative advantages of water over land transport" (Eastman, 1988: 106), marking transport in the North "far more arduous, slow and expensive than in the South" (ibid, 64); see also Kim (2008) and Evans (1984: 298).
} 
The comparative element of our study provides analysis of monthly grain prices for Belgian markets (1765-1794), French départements (18001872) and English counties (1770-1820), as well as annual data for German (1700-1800) and European markets (1700-1820), respectively. Adopting identical methodology to that in our Qing price analysis, and (for the most part) identical data frequency, this exercise empirically confirms the notion expressed in parts of the social and economic history literature that China's Great Divergence from European levels of market integration was already well under way several decades before the end of the $18^{\text {th }}$ century.

We subject our findings of Chinese market disintegration to a host of robustness checks, related to alternative crops, the sample of prefectures analysed, and the reference price adopted in the convergence regressions. We also investigate whether nonlinear adjustment dynamics may have distorted our linear convergence analysis (Taylor, 2001) and consider alternative specifications to capture common shocks and network effects.

Our empirical methodology is rooted in a general equilibrium perspective, which postulates that location-specific grain prices are jointly determined by factors such as local and global weather shocks and by a market's relative position in the existing trading network. This implies that the investigation of price convergence between any two markets - which is the methodology of the cointegration approach to market integration ${ }^{3}-$ can be misleading, unless we take account of the outside options available to consumers and traders as well as the relative attractiveness of these opportunities. Furthermore, bilateral price movements in reaction to common shocks may make price pairs appear to co-move, although the cause for this co-movement is entirely unconnected to spatial arbitrage.

Our conceptual framework incorporates a mechanism akin to the notion of multilateral resistance in the gravity model of bilateral trade flows

\footnotetext{
${ }^{3}$ Additional concerns for this approach arise from the assumption of nonstationary price series, both theoretically (Deaton and Laroque, 1992, 1996) and empirically (our panel unit root tests reject nonstationary prices for all Chinese and European samples).
} 
(see Head and Mayer, 2014, for a recent survey) and the third country effect in the analysis of exchange rate movements (Berg and Nelson, 2015). The network aspect of price movements, both with regard to multilateral resistance and common shocks, manifests itself in our observed price series in what econometricians refer to as 'cross-section dependence' (Andrews, 2005; Coakley, Fuertes and Smith, 2006; Chudik and Pesaran, 2013). Failure to address this dependence in the empirical strategy can result in misleading inference and inconsistent estimators (Phillips and Sul, 2007; Sarafidis and Wansbeek, 2012). ${ }^{4}$

We introduce a simple theoretical model of grain price behaviour which incorporates the network dependence aspect of trade (and thus grain prices) and of exogenous (e.g., weather) shocks to production by means of a multifactor error structure. This framework accounts for the fact that locationspecific prices are determined within a general equilibrium system. Our empirical investigation builds on the Pesaran (2006) common correlated effects (CCE) estimator to investigate heterogeneous price convergence to the regional or macro-regional average. ${ }^{5}$ In contrast to existing work on market integration our estimator is robust to but does not rely on certain time series properties of the data (nonstationarity, cointegration) to establish (or reject) long-run price convergence across prefectures.

The remainder of this paper is organised as follows: Section II introduces the data and methodology employed. Section III discusses the empirical findings and provides robustness checks. Section IV concludes.

\footnotetext{
${ }^{4}$ The literature distinguishes between strong cross-section dependence, which is pervasive, and weak cross-section dependence which represents a spatial process with distance decay (Bai and Ng, 2002; Bailey, Kapetanios and Pesaran, 2015). From an empirical point of view ignoring the former can lead to bias whereas ignoring the latter will merely lead to misleading inference. Geweke (1977) and Sargent and Sims (1977) were among the first to employ a factor structure to model strong dependence, which does not require a priori knowledge of the cross-sectional ordering of units (in our case markets). The spatial econometric literature has a long tradition of modelling weak dependence by relating each unit to its neighbours (adopting a pre-defined distance metric to specify neighbourhood), going back to Moran (1948) and Whittle (1954) and popularised by the work of Cliff and Ord (1973) and Anselin (1988).

${ }^{5}$ Alternatives (e.g. convergence to the provincial average or a specific reference price in the prefecture hosting the provincial capital) are also considered in an online Appendix.
} 


\section{Data and Methodology}

\section{II.1 Data}

We briefly introduce the Chinese and European data used in our analysis more details (including maps) are contained in an online Appendix.

\section{Qing China}

We use monthly prices ${ }^{6}$ for rice $^{7}$ and wheat over the period $1740-1820$ from 131 prefectural markets (located in 11 provinces) in South China and from 80 prefectures (located in 6 provinces) in North China. Thus, our data capture all but one (Yunnan) of the 18 provinces of Qing China Proper. ${ }^{8}$ These prices were collected by the Qing state as part of an elaborate grain price reporting system, which was progressively implemented during the reign of Emperor Kangxi (1662-1723) and became a nation-wide system at the start of the reign of the Emperor Qianlong (1736-1795). We use the subset of rice and wheat prices, recorded in taels (liang, ounces of silver) per granary bushel (cang shi, around 104 litres), compiled by the late Professor Wang Yejian [Yeh-Chien] and collaborators. There is a general consensus in the literature that there is a high degree of veracity in these data series and that they are comparable across locations (Chuan and Kraus, 1975; Marks, 1991, 1998; Shiue, 2002, 2004, 2015; Shiue and Keller, 2007).

\footnotetext{
${ }^{6}$ As monthly highest price and lowest price for each prefecture are available we follow the literature and use their average as the monthly price. See section III.2 for robustness checks. ${ }^{7}$ In the Qing Price Report System, rice prices were disaggregated into (among others) $1^{\text {st }}$ grade rice (superior), $2^{\text {nd }}$ grade rice (medium), and $3^{\text {rd }}$ grade rice (common). For best coverage we use medium grade rice for Southern China with the exception of Zhejiang Province where in the absence of alternatives we select polished early-ripening rice. Our results are qualitatively unchanged if we omit the Zhejiang prefectures from the sample (see online Appendix for details). See also section III.2 for robustness checks using common and superior grade rice prices.

${ }^{8}$ For models that adopt cross-section averages within the Skinner (1977a) macro-regions framework (see below) we are forced to drop two prefectures in Northern China from the sample since these represent 'isolates' (i.e. the only prefectures within a designated macroregion) and thus macro-region averages are identical to prefectural price series.
} 
Our analysis is split in two on the basis that South China produced rice while North China produced wheat as the main staple grain crop during this period (Buck, 1937: Map 3). ${ }^{9}$ We have on average over 730 (785) time series observations for each of the 131 (80) Southern (Northern) prefectures. ${ }^{10} \mathrm{We}$ selected the sample period January 1740 to December 1820 as this ensures that the changes in market integration we identify below were predominantly driven by internal market-related factors in China rather than externally-driven political turmoil or technology and trade shocks that increasingly affected China in the $19^{\text {th }}$ century.

Our analysis further uses several geospatial datasets, which help us match prefectural grain price data to information on politico-bureaucratic, geomorphological and agro-climatic borders. We employ Harvard's China Historical Geographic Information System (CHGIS) maps for the boundaries of the administrative hierarchy (prefectural and provincial borders) at our sample end point in 1820. Mountain ranges and other geomorphological features can act as natural barriers to trade, and we employ information on boundaries for eight 'physiographic macro-regions' introduced by William Skinner (1977a). ${ }^{11}$ Skinner's (1977a) classification identifies functional units, emphasizing the inter-relatedness rather than the uniformity of characteristics: each macro-region is characterized by a concentration of arable land,

\footnotetext{
${ }^{9}$ Wheat was a luxury grain for many in the North, who instead consumed millet and sorghum, though prices of all three grains were closely correlated (Li, 2000). See section III.2 for robustness checks using millet prices.

${ }^{10}$ Our panel is unbalanced with on average $19 \%$ of observations missing in each regional sample - plots for average as well as maximum and minimum number of observations in a 20year rolling window convergence regression are presented in the online Appendix. Our heterogeneous panel econometric approach avoids the undesirable weighting implicit in pooled regressions of unbalanced panel data and thus is robust to this data feature. We convinced ourselves that the differential data availability across prefectures and time does not drive our empirical results (see online Appendix).

${ }^{11}$ Most of the boundaries adopted by Skinner follow watersheds and the crests of mountain ranges: the high-density 'core' city of each macro-region is located in the river-valley lowlands and surrounded by concentric gradients of declining population densities until reaching the periphery. The river basin is taken as the essential macro-regional determinant because of the importance of water transport and since crop inventories and productive techniques were specifically adapted to a plains-and-valley ecology (Skinner, 1977b). Note that the Northeast China (Manchuria) macro-region (\#10) is not part of our sample.
} 
population, capital and other 'resources' at its core, and by "the thinning out of [these] resources toward the periphery" (216). Skinner (1977a) argued that macro-regions were subject to differential development cycles and that the majority of trade took place within rather than across macro-regions. In robustness checks we employ the agricultural areas developed by Buck (1937: Map 4). Detailed maps for these geospatial classifications are contained in the online Appendix.

\section{Austrian Low Countries (Belgium)}

Our Belgian dataset comprises 20 markets between January 1765 and November 1794 (3.5\% missing observations), providing wheat prices observed on the first market day of the month, as collated and recorded in Vandenbroeke (1973). Data collection was standardized and carried out by central government customs officials who also converted measurements to a common unit - Brabantine stuivers per razier from Brussels (49 litres). Buyst, Dercon and Van Campenhout (2006: 188) suggest that these markets "compose a representative sample of all large and medium-sized grain markets in the Austrian Low Countries".

\section{England}

We adopt the English Corn Returns, weekly price series for selected grains in a variety of locations published in the London Gazette, the official government newspaper, between 1700 and 1914. For our purposes most relevant are the weekly wheat prices from November 1770 to September 1820 collected and digitized by Brunt and Cannon (2013, 2014), covering 40 counties (all of England excluding London). Like in the case of the Qing price series, government officials collecting these data sought to provide an accurate picture of grain price movements across the country.

The data $(0.3 \%$ of missing observations) are prices per Winchester bushel of wheat (about 35.2 litres) in shillings and pence, representing county 
average prices over the previous week. From these records we extract monthly prices, the same data frequency as that of the Qing grain prices. ${ }^{12}$

\section{France}

From Labrousse, Romano and Dreyfus (1970) we obtain monthly average wheat prices in 85 départements for the period September 1800 to December 1872 (below we limit our presentation to analysis up to 1825), collected by French ministerial officials and first published in the 1870s. Our sample covers the entire French mainland, and has only $0.6 \%$ of observations missing. ${ }^{13}$ All prices are in francs per hectoliter.

\section{Germany}

We adopt average annual rye prices in grams of silver per hectoliter for 12 cities from Rahlf (1996). The geographic distribution of these markets is skewed towards the Rhineland and surrounding areas (Aachen, Düren, Köln, and Xanten) as well as Southern Germany (Augsburg, Frankfurt, München, Speyer, Strassburg, and Würzburg), with only two markets, Leipzig and the Prussian city of Danzig, in the North or East of the country. The time series of these data cover 1500 to 1800 (17\% of observations missing), though below we limit our presentation to results for the $18^{\text {th }}$ century ( $9 \%$ missing). ${ }^{14}$

\footnotetext{
${ }^{12}$ We know from the work of Taylor (2001) and Brunt and Cannon (2014) that temporal aggregation (averaging) of prices has a significant biasing impact on estimates of convergence (and associated half-lives) and therefore pick prices for the first week recorded every month instead. Using any other week yields qualitatively identical results (available on request). We also use the full weekly data available as a robustness check (see online Appendix).

${ }^{13}$ The data tables in Labrousse et al (1970) are divided into 1800-1805 covered by the French Republican Calendar and 1806-1870s in the Gregorian calendar, so that we convert the former into the latter standard.

${ }^{14}$ One difficulty is the differential definition of the time dimension, which for Aachen, Augsburg, Düren, Frankfurt, Köln, Leipzig, München, Speyer, and Würzburg is the harvest year, whereas for the three remaining cities data are based on the calendar year. Following the literature we adjust the data by computing the simple average for consecutive years in those series that are for the harvest year.
} 


\section{European markets (cross-national sample)}

Average annual wheat prices in grams of silver per litre for 55 markets across Europe are taken from the Global Commodity Prices Database collated by Bob Allen and Richard Unger. Our sample selection is exclusively based on data availability for the 1700-1820 time horizon, and we only include cities for which observations cover at least $50 \%$ of this period. ${ }^{15}$

\section{II.2 Empirical Framework}

We begin with a price model for an agricultural commodity in multiple markets $i$ at time $t$ with an inelastically supplied local harvest output $h_{i t}$, which follows a stochastic process characterized by the cumulative distribution function $\Phi(h, H)$, where $\Phi(h, H)=\operatorname{Pr}\left(h_{i, t+1} \leq H_{i t} \mid h_{i t}=h_{i}\right)$. We specify that the price $P_{i t}$ in location $i$ at time $t$ is not exclusively determined by local harvest output $h_{i t}$ but by a host of other factors like harvest conditions in other markets, weather shocks that affect multiple locations, relative trading costs between location $i$ and other locations and the management of grain storage in $i$ relative to other locations. ${ }^{16}$ We model this general equilibrium dependence in a very flexible way by employing a vector of unobserved common factors $\boldsymbol{f}_{t}$ at time $t$ with market-specific 'factor loadings' $\boldsymbol{\lambda}_{\boldsymbol{i}}$. For example, if the component $k$ of $\boldsymbol{f}_{t}$ pertains to a common weather shock affecting multiple locations, the corresponding factor loading $\lambda_{i}^{k}$ captures the location-specific impact of this weather shock. A non-zero factor loading in locations $i$ and $j$ would suffice to induce cross-sectional price dependence. ${ }^{17}$ The local price

\footnotetext{
${ }^{15}$ Like in the German data these price series represent a mix of harvest year and calendar year averages which need to be adjusted to make price series comparable across markets.

${ }^{16}$ The Qing state actively interfered with grain markets in a number of ways, including direct control of supply and marketing, provisions for troops, reduced price sales, disaster relief ( $\mathrm{Li}$ and Dray-Novey, 1999) as well as grain tribute for the imperial capital and a network of civilian granaries (Will and Wong, 1991; Shiue, 2004; Li, 2007). Local officials managed granaries but the central state set the storage targets. Their intended purpose was to provide food relief in the event of harvest shortages and to help smooth price fluctuations through release of grain at various times in the growing and harvest cycle ( $\mathrm{Li}, 2007)$.

${ }^{17}$ We implicitly assume that $\operatorname{Cov}(h, f)>0$, which creates the direct link between harvest and the unobserved common factors across markets.
} 
can then be written in form of a (deterministic) log-linear inverse demand function

$$
\ln P_{i t}=a_{i}+b_{i} h_{i t}+\lambda_{i}^{\prime} \boldsymbol{f}_{t}
$$

where $a(>0), b(<0)$ and $\lambda$ are location-specific parameters. ${ }^{18} \mathrm{We}$ assume that consumers are the only buyers in the market and price behavior is driven by production decisions and stochastic harvest outcomes. ${ }^{19}$

In a pre-modern agrarian economy with limited technological progress (such as Qing China) we assume that shocks to harvest output are exogenous, determined by the conditions in agricultural production (typically weather shocks). However, our setup recognizes that widespread flooding or locust plagues or civil strife ${ }^{20}$ or other shocks ${ }^{21}$ to market $i$ are likely not confined to arbitrary prefectural boundaries, but are also going to affect the harvest in close-by market $j$ : harvest outcomes themselves are correlated across markets. ${ }^{22}$ Further, since local Qing officials actively engaged in grain markets through the management of civilian granaries our setup also captures the effect of correlated public granary management across prefectures in response to common harvest shocks.

Following into the footsteps of a long literature, we conceptualize the degree of market integration by a dynamic convergence process in which markets are more integrated the quicker prices return to their equilibrium level

\footnotetext{
${ }^{18}$ Fackler and Goodwin's (2001: 1017) review of spatial price analysis concludes that empirical tests are "sensitive to the factors such as transaction costs and other unobserved variables that may influence the responses of agents." Transaction costs are nominally captured by $a_{i}$ in standard price models, thus a further interpretation of $\lambda_{i}^{\prime} \boldsymbol{f}_{t}$ in equation (1) would be that transaction costs may follow a more complex dynamic evolution.

${ }^{19}$ The imperial ban on speculation and hoarding of grain by private merchants during the Qing Dynasty can be taken as a motivation for this assumption commonly made in the literature.

${ }^{20}$ Between 1470 and 1900, there were a total of 249 officially recorded localized civil conflicts in China. Peasant revolts in particular were closely related to agricultural harvest output (Jia, 2014).

${ }^{21}$ For instance, the inflow of silver into China during the second half of the $18^{\text {th }}$ century affects the grain price in the economy but to a different extent across markets ( $\mathrm{Li}, 2009$; Shiue, 2004).

${ }^{22}$ We are agnostic over the reach of such shocks, our empirical implementation is robust to localised shocks as well as global ones which affect all prefectures in the region.
} 
following a shock. In this setup, 'return to equilibrium' pertains to the change in the nominal price $P_{i t}$ in location $i$ relative to an 'equilibrium proxy' $\bar{P}_{t}$, defined as $\tilde{p}_{i t}=\left(\ln P_{i t}-\overline{\ln P_{t}}\right)$. Price convergence is then modeled by the following convergence equation:

$$
\Delta \tilde{p}_{i t}=\beta_{i} \tilde{p}_{i, t-1}+\boldsymbol{\gamma}_{i}^{\prime} \boldsymbol{f}_{t}+\varepsilon_{i t}
$$

where the dependent variable, $\Delta \tilde{p}_{i t}=\tilde{p}_{i, t}-\tilde{p}_{i, t-1}$, is the change in the relative price between times $t-1$ and $t$. The first term on the right-hand side contains our parameter of interest, $\beta_{i}$, which is the location-specific speed of convergence parameter. If there is no convergence, a shock will have a permanent effect on price movements and $\beta_{i}$ will be to zero. Convergence implies that $\beta_{i}$ will be negative and the magnitude of $\beta_{i}$ measures the convergence speed: the larger the value of $\beta_{i}$ (in absolute terms), the faster prices will converge back to their equilibrium after a shock. Presuming that price differentials are dissipated by economic agents seeking profits from arbitrage, more integrated markets are associated with more arbitrage activities resulting in a higher speed of convergence. For points of comparison, the speed of convergence can be measured by the associated 'half-life', calculated as $\ln (0.5) / \ln \left(1+\beta_{i}\right)$, which gives the number of time periods (in our case: months) until half the effect of a shock dissipates.

If nominal prices follow a multifactor error structure, as we assumed in equation (1), then the convergence dynamics of the relative price $\tilde{p}_{i t}$ will also follow this error structure: the second term in equation (2), $\boldsymbol{\gamma}_{i}^{\prime} \boldsymbol{f}_{t}$, accounts for the fact that the changes in relative prices will also be affected by locationspecific responses to common shocks. ${ }^{23}$

\footnotetext{
${ }^{23}$ The factor loading $\gamma_{i}$ in equation (2) differs from that in equation (1), $\boldsymbol{\lambda}_{i}$, as a result of the derivation of the relative price equation (available on request). Note further that our multifactor error structure encompasses the inclusion of a location-specific intercept.
} 
The inclusion of the multifactor error factor structure distinguishes our convergence equation from that in other papers, most notably Goldberg and Verboven (2005) and Fan and Wei (2006), who assess market integration in $20^{\text {th }}$ century Europe and China, respectively. Our empirical implementation makes use of novel techniques from the panel time series literature which allow us to study price behavior in diverse sets of markets while accounting for the network effect of trade and the heterogeneous impact of common price shocks such as floods, droughts, or civil unrest. In addition the long time series dimension of the data enables us to study the dynamic evolution of price convergence over time.

The empirical implementation of the convergence equation (2) requires us to specify an 'equilibrium proxy' to which a prefectural price is assumed to converge. Although we examined many candidates in our research, we will discuss and present our results for two proxies: the average prefectural price over the larger domains of North and South China, and the average prefectural price in each of Skinner's (1977a) physiographic macro regions. ${ }^{24}$ Our main variable of interest is then the relative grain price (in logs) defined as $L P R_{i t}=$ $\ln \left(P_{i t} / \bar{P}_{r t}\right)$, where $P_{i t}$ is the prefectural price and $\bar{P}_{r t}$ is the average prefectural price over the respective region (North or South China) at time $t$. Our main estimating equation is then given by:

$$
\begin{aligned}
\Delta L P R_{i t}= & \alpha_{i}+\beta_{i}^{L P R} L P R_{i, t-1}+\sum_{\ell=1}^{p_{i}} \delta_{i, \ell} \Delta L P R_{i, t-\ell} \\
& +\phi_{i} \overline{\Delta L P R}_{t}+\varphi_{i} \overline{L P R}_{t-1}+\sum_{\ell=1}^{p_{i}} \xi_{i, \ell} \overline{\Delta L P R}_{t-\ell}+\varepsilon_{i t},
\end{aligned}
$$

where the dependent variable is defined as $\Delta L P R_{i t}=\ln \left(P_{i t} / \bar{P}_{r t}\right)-$ $\ln \left(P_{i, t-1} / \bar{P}_{r, t-1}\right)$ and our speed of convergence parameter is denoted by $\beta_{i}^{L P R}$. The parameter $\alpha_{i}$ captures location-specific time-invariant heterogeneity,

\footnotetext{
${ }^{24}$ In the online Appendix we also provide results for convergence to the provincial average price. Additional specifications adopt a specific market (e.g. the prefecture hosting the provincial capital) in the construction of the relative price series (see below and in the online Appendix).
} 
which will help explain price wedges across diverse locations (e.g. due to remoteness).

The last term on the first line of (3) contains lags of the dependent variable, which account for possible serial correlation and capture short-run behavior. ${ }^{25}$ The second line in (3) contains cross-section averages of the dependent and independent variables following Pesaran's (2006) Common Correlated Effects (CCE) approach to capture the impact of common shocks and the trade network. ${ }^{26}$ The cross-section averages $(\overline{\triangle L P R}, \overline{L P R})$ included in (3) are the averages based on physiographic macro regions of China (Skinner, 1977a), since unobserved heterogeneity due to weather patterns, flooding, etc. are likely better captured within these units. ${ }^{27}$ Taken together the $\overline{\Delta L P R}$ and $\overline{L P R}$ terms capture the unobserved common factors, while the prefecturespecific parameters $\left(\phi_{i}, \varphi_{i}\right.$ and $\left.\xi_{i, \ell}\right)$ allow for their heterogeneous factor loadings. ${ }^{28}$ In the analysis of European markets we investigate convergence to the national average price (in the cross-European sample: cross-national average) and adopt cross-section averages for the respective full sample.

The above empirical equation yields a total of $N$ heterogeneous convergence coefficients (one for each prefecture/market) and we report the (Common Correlated Effects) Mean Group estimate $\hat{\beta}_{M G}^{L P R}=\sum_{i=1}^{N} \omega_{i} \hat{\beta}_{i}^{L P R}$ of this set of coefficients (Pesaran and Smith, 1995; Pesaran, 2006) together with its $95 \%$ confidence interval. ${ }^{29}$ Because this mean group estimate is a weighted

\footnotetext{
${ }^{25}$ The number of lags $p_{i}$ in each prefecture regression is determined by the Schwarz-Bayesian Information Criterion (IC). Alternative use of the Akaike IC appears not to influence results in any significant way.

${ }^{26}$ This aside we include centered seasonal (monthly) dummies to capture the effect of heterogeneous harvest seasons across China's different agro-climatic areas. The construction of these (orthogonalized) seasonal dummies follows the suggestion in Juselius (2006).

${ }^{27}$ Using cross-section averages for the entire region (South, North) or by agro-climatic region (Buck, 1937) produces similar results of secular market disintegration (see online Appendix).

${ }^{28}$ The simple algebra capturing the intuition of this approach is presented in Eberhardt, Helmers and Strauss (2013).

${ }^{29} \mathrm{We}$ follow the standard in the literature and employ robust regression to estimate weighted averages $\left(\sum_{i=1}^{N} \omega_{i}=1\right)$ which are robust to outliers (Hamilton, 1992). Standard errors are computed non-parametrically following Pesaran and Smith (1995). Our Mean Group estimates of price convergence (see below) are unbiased but inefficient if our assumption of heterogeneous convergence is false. Adopting a pooled version of the CCE estimator (see
} 
average of location-specific convergence terms, it as an economy-wide measure of the degree of overall market integration.

Theoretical work and simulations have shown that the simple augmentation with averages in equation (3) is extremely powerful, providing consistent estimates in the presence of nonstationary factors, structural breaks, and cointegration or noncointegration of the model variables (Kapetanios, Pesaran and Yamagata, 2011; Pesaran and Tosetti, 2011; Westerlund and Urbain, 2015). ${ }^{30}$

\section{Empirical Results}

\section{III.1 Price Convergence in China and Europe}

Instead of analyzing price convergence over the entire time horizon in a single regression model, the detailed time-series dimension of our data permits us to investigate the time paths of 20 -year rolling windows. ${ }^{31}$ This permits us to capture any structural change in the convergence process over time and also to present the empirical results from this exercise in graphical form. ${ }^{32}$ We carry out a wide range of robustness checks detailed in Section III.2.

We begin with our analysis of market integration in Qing China. Figure 1 provides three sets of results for the evolution of price convergence in North (dashed line in each plot) and South China (solid line). Since the first of our rolling windows is over the period 1740-59, the first speed of convergence

\footnotetext{
online Appendix) yields lower speed of convergence and the same secular decline we find in our main results below.

${ }^{30}$ Further details on this empirical approach can be found in applications on returns to R\&D (Eberhardt, Helmers and Strauss, 2013) and the public debt and growth nexus (Eberhardt and Presbitero, 2015).

${ }^{31}$ The window moves one year at a time to avoid seasonal impacts. The choice of 20 years is arbitrary, but results are qualitatively identical if we use 15- or 10-year windows instead (see online Appendix). For the monthly European data we adopt the 5-, 10-, and 20-year windows here and in the online Appendix, for the annual data we choose a 60-year window.

${ }^{32}$ A further advantage of examining convergence over 20 year subsamples that it allows the factor loadings $\boldsymbol{\gamma}_{i}$ to vary across periods.
} 
estimate in Figure 1 is dated at 1759. The (second) speed of convergence estimate at 1760 pertains to the period $1741-1760$ and so on.

In Figure 1(a) we present robust (CCE) Mean Group estimates for regional convergence, $\hat{\beta}_{M G}^{L P R}$, where region refers to the entire North or South. Recall that the larger (in absolute terms) the convergence estimate, the faster prefectural prices converge to the regional average price. Our first observation is that the convergence speed is higher for the South than the North. Our second observation is that regional convergence estimates in both regions follow an upward trend over time, which implies regional markets became less integrated over time. ${ }^{33}$

We can quantify this dramatic decline by computing estimates for the half-life of the price convergence process: ${ }^{34}$ for South China the speed of convergence in the mid- $18^{\text {th }}$ century implies that half the effect of a given shock would dissipate in around 8 months; over the two decades before the turn of the $19^{\text {th }}$ century this had slowed to 19 months, while a decade later the figure was 54 months, before some recovery to around 28 months at the end of our sample period. For North China the equivalent figures at these points in time are $13,34,64$ and 47 months. ${ }^{35}$

\footnotetext{
${ }^{33}$ An alternative interpretation of our setup is that of a unit root test for relative price movements: if the null of a unit root is rejected, prices do converge (without any concern over the predicted time horizon for convergence). We apply this interpretation in the online Appendix, using Monte Carlo simulations to provide critical values for an averaged t-statistic on $\beta_{i}^{L P R}$. We find that we can no longer reject a unit root for the relative price series ( $10 \%$ level of significance) for North and South China from 1785 and 1790 onwards, respectively: from these dates onwards grain markets in North and South China were fragmented.

${ }^{34}$ For comparison with modern day data, Crucini and Shintani (2008) estimate persistence in law of one price deviations for a large number of goods and cities, finding a half-life of 19 months for the median good in OECD cities, 12 months for cities in less developed countries and 18 months for US cities. Goldberg and Verboven (2005) estimate median half-lives of relative price deviations for automobiles in European markets between 16 and 19 months. Fan and Wei (2006) find dramatically lower half-lives between 0.3 and 5 months across a large range of products in 36 Chinese cities for the 1990-2003 time period. Note that none of these studies accounts for cross-section dependence or changes in convergence over time.

${ }^{35}$ The specific dates, mean speed of convergence estimates and half-lives are as follows: in South China, for the rolling window 1740-59, -0.083 [8.0 months]; 1780-99, -0.035 [19.3]; 1789-1808 (minimum speed of convergence), -0.013 [54.0]; 1801-20, -0.025 [27.9]. In North China for 1740-59, -0.051 [13.2 months]; 1780-99, -0.020 [33.9]; 1789-1808, -0.011 [64.4];
} 
Our empirical implementation underlines the assumption that common shocks and the network effect primarily operate within certain geographical bounds, as indeed was suggested by Skinner (1977a) with regards to macroregions. Pomeranz (2000: 22, emphasis added) argues that up until the 1780s "markets worked well within China's eight or nine macro-regions", ${ }^{36}$ which could imply price convergence at the macro-region level rather than the regional (South/North) level we investigated above. In Figure 1(b) we study this possibility by employing the mean price for each Skinner macro-region as the reference price.

The overall patterns in the resulting convergence graphs closely follow those discussed above. In quantitative terms, the results for North China in Figures 1(a) and (b) match each other more closely than those for South China (graphs providing these direct comparisons are presented in an online Appendix): the geographical area at which convergence is hypothesized to take place is substantially reduced in the Southern sample, where we distinguish six macro-regions, but remains relatively large in the Northern sample, where there are only two macro-regions. This robustness check is important because we detect market disintegration over time even when specifying convergence to smaller, 'functional' geographic units, and because the deviations in magnitude vis-à-vis our results in Figure 1(a) are as expected given the relative geographical distances at play.

What happens to our finding of market disintegration if we (i) do not account for cross-section dependence (common shocks and trade network effects), and (ii) calculate a single estimate of the average speed of convergence for the entire time horizon? Figure 1(c) provides answers to these questions: ignoring cross-section dependence leads to convergence estimates

1801-20, - 0.015 [47.5]. The minimum speed of convergence in North China is for the period 1791-1810: -0.004 [163.1].

${ }^{36}$ Eastman (1988: 120) conveys the same sentiment when stating that commercial interaction between macro-regions was 'slight'. 
which are significantly higher than those in our previous specifications. ${ }^{37}$ Additionally ignoring changes in the speed of convergence over time we can obtain robust mean estimates (and implied half-lives) of -0.059 (11.5 months) in the North and -0.054 (12.6 months) in the South. ${ }^{38}$

In summary, Figure 1 suggests that grain markets in China were more integrated in the South than the North, and that both regions suffered a process of prolonged market disintegration during the $18^{\text {th }}$ century. ${ }^{39}$ It further demonstrates that two core elements of our empirical strategy, namely accounting for cross-section dependence and the analysis of changes in market integration, are instrumental in establishing this result.

Although the recent literature on market integration in Qing China overwhelmingly sides with Shiue and Keller (2007), suggesting that with regard to market integration "all was well and good with China in the eighteenth century" (Sng, 2014: 108), there does exist a variety of historical (and a few quantitative) accounts describing a secular decline during the second half of the $18^{\text {th }}$ century already. From the narratives developed by these authors we can extract four intertwined factors potentially explaining a decline in market integration: (i) population pressure on arable land, especially in grain surplus regions, ${ }^{40}$ which led to a decline in trade between these and the advanced regions on the Eastern Seaboard (Eastman, 1988: 242; Li, 2007: 109; Perkins, 1969; Pomeranz, 2000: 13, 22, 85, 184); (ii) environmental degradation affecting farming and transport, primarily in form of "inherently instable" water control systems which were in an "adversarial" relationship

\footnotetext{
${ }^{37}$ The analysis in this graph is based on convergence to the regional average price. Note that we omit the substantial downward movement in the convergence estimate for North China (i.e. an increase in market integration) to maintain the same scale on the vertical axis as in the two previous graphs.

${ }^{38}$ We compute these estimates as robust means across the 62 estimates from our 20 -year rolling window analysis. If we instead estimate a single coefficient from the entire 81 -year panel we find somewhat higher half-lives of 15-18 months (depending on specification of the short-run dynamics) in the South and 19-21 months in the North.

${ }^{39}$ Price convergence results for individual provinces as well as individual macro-regions (reported in the online Appendix) confirm that these average results are not driven by individual outlier provinces or macro-regions.

${ }^{40}$ These include Guangxi, Hunan, Jiangxi, Sichuan (South), Hunan and Shaanxi (North).
} 
with the environment (quotes from Elvin, 2004: 115 and 120-8; see also: Li, 2007: 109; Fairbank and Goldstein, 2006: 171; Marks, 1998; Pomeranz, 2000: 228; Richardson, 1999: 22f); (iii) technological factors, namely the absence of significant advances in transport technology or infrastructure (Kim, 2008: 231; Rawski 1972: 4-5; Watson, 1972; Wiens, 1955: 248f) and agricultural technology (Elvin, 1973; Eastman, 1988; Perkins, 1969; Pomeranz, 2000: 22); and (iv) a decline in the capacity of the Qing state to uphold and further market integration, in part driven by fiscal weakening and by "grain protectionism" on behalf of local officials whose paramount concern was to 'nourish the people' to avoid civil strife (Cheung, 2008: 116; Marks, 1998: 12; Pomeranz, 2000: 250; Shiue, 2015; Sng, 2014)

How do the results for China compare with those for price convergence in European markets? In Figure 2(a) we present our convergence estimates for North and South China alongside those from a number of national grain price samples (Belgium, England, France, and Germany) and a cross-European wheat price sample which were analyzed using the same methodology as above (see table footnote for additional details). In order to make results from samples with different data frequency comparable we plot the implied half-lives (in months) for each convergence result. Our presentation in Figure 2 is limited to results for the $18^{\text {th }}$ and early $19^{\text {th }}$ centuries; we also dispense with confidence intervals to aid illustration detailed convergence plots for each European sample adopting various rolling window lengths are contained in an online Appendix.

At the bottom of Figure 2(a) and thus the economy with the highest level of market integration we find the English counties (weekly data), ${ }^{41}$ followed by the other national samples for Belgium, France and Germany, and finally the cross-European market sample. The finding that, based on the results for monthly price series, Belgian market integration in the late $18^{\text {th }}$

\footnotetext{
${ }^{41}$ Note that although we do see a difference between the weekly and monthly data results for England, these estimates still suggest that use of monthly data does not vastly overestimate the half-life of grain price integration during the late $18^{\text {th }}$ and early $19^{\text {th }}$ century.
} 
century was superior to that of English counties can be explained by the former's high quality road network (Buyst et al, 2006: 193), the absence of some underdeveloped regions in the sample (Limburg and Luxembourg) and the comparatively small geographic size of the country. ${ }^{42}$ The different nature of the price data used, namely observed prices on specific days in specific markets for Belgium, and prices averaged across time (week) and space (county) for England, will also contribute to an upward bias in the English half-lives (Taylor, 2001). The higher half-life for French départements compared with English counties can be linked to "higher trade costs [in France] than Britain due to smaller density, geography, internal barriers, limited development of new methods of distribution and more limited investment in transport infrastructures" (Daudin, 2010: 717). ${ }^{43}$ The German sample is limited to merely 12 cities, spread over a large geographical area, which may explain the relatively larger half-life compared with other national markets. Our results for cross-European markets indicate lower levels of market integration than in the national markets, which is not surprising given the significant cultural, political and climatic heterogeneity, not to mention greater distances, in the former. No doubt the bias introduced by adopting annual averages for the German and European price series also plays a role in explaining their larger half-lives than those of the other economies for which we have monthly data (Brunt and Cannon, 2014; Taylor, 2001).

Crucially, our two Chinese samples clearly differ in their secular evolution of market integration from the other samples which were analyzed using identical methodologies, and, in case of the English (monthly), Belgian

\footnotetext{
${ }^{42}$ East-West expanse from Tienen to Nieuwpoort around 100 miles, from Norfolk to Cornwall around 350 miles. North-South expanse from Antwerp to Binche around 50 miles, from Northumberland to Devon around 320 miles. When we restrict the English sample to 15 counties of the South-East (all counties to the East of the quarter-circle from Norfolk to Hampshire), the convergence rate among these markets is on par with that of our Belgian sample (available on request).

${ }^{43}$ Our sample period predates the "ambitious plan of repairing and extending inland navigation" and the later dominance of rail transport, with canals still the "principal means of transport" (Ejrnæs and Persson, 2000: 153).
} 
and French price series, identical data frequency. While the levels of market integration in the 1750s were quite similar between China's North and South on the one hand and European markets on the other, China witnessed a secular decline in market integration which reached its 'peak' in the early 19th century, when Northern (Southern) Chinese markets had estimated half-lives roughly 15 (five) times those of European markets. This contrast is even starker if we compare results for our Chinese samples with those for the national samples of Belgium, France and England. ${ }^{44}$

Figure 2(b) reports estimated half-lives for a number of prominent Chinese macro-regions (alongside some of the European markets for reference) to illustrate that market disintegration during the second half of the $18^{\text {th }}$ century was pervasive across all regions of China, including the commercially most advanced Lower Yangzi macro-region. ${ }^{45}$

\section{III.2 Robustness Checks}

Since the results for Qing China clearly deviate from those for European markets we carry out various robustness checks for our finding of secular market disintegration. These can be grouped into four categories: (i) related to alternative crops; (ii) related to the sample of prefectures analyzed or the reference price adopted in the convergence analysis; (iii) related to the nature of the dynamics of convergence, namely linear or nonlinear; and (iv) related to the cross-section dependence we capture in our cross-section averageaugmented convergence regressions. We discuss these in turn below. Detailed results for all robustness checks are confined to an online Appendix. ${ }^{46}$

\footnotetext{
${ }^{44}$ At the end of the Qianlong reign in 1795 (the end of the sample period in Shiue and Keller, 2007) the Southern and Northern Chinese markets had half-lives around six and 12 times those of English markets, respectively. By 1810 these ratios had increased to half-lives roughly 22 and 78 times those of the English markets (all comparisons based on monthly data).

${ }^{45}$ This analysis by macro-region also addresses concerns that the geographical dimensions of North and South China are substantially larger than those of the European economies studied. ${ }^{46}$ As a reminder we note the following robustness checks we already indicated above: use of 10- or 15-year rolling windows; treatment of the convergence regression as a linear unit root test; and convergence analysis for individual provinces as well as individual macro-regions.
} 
(i) In the above analysis we use prices for wheat in the North and medium $\left(2^{\text {nd }}\right)$ grade rice in the South. Li $(2000,2007)$ refers to wheat as a 'luxury good' and suggests that millet and sorghum were Northern Chinese staple crops (see also Perkins, 1969: 6), while Marks (1991: 70) claims that 'common' $\left(3^{\text {rd }}\right)$ grade rice "represented the bulk of grain traded in the markets" of Lingnan. We conduct our price convergence analysis for millet as well as superior $\left(1^{\text {st }}\right)$ and common grade rice to find qualitatively identical results of disintegration. ${ }^{47}$

Following the recent literature (esp. Shiue and Keller, 2007) our analysis employs the monthly average grain price computed from the prefectural low and high price reported in the historical records. Over time high and low prices may consistently come from specific locations within the prefecture, e.g. the high price may refer to the prefectural capital (Marks 1998: 11) and the low price to a remote county, such that their separate analysis may indicate whether the use of the average grain price and thus our level of aggregation misses important within-prefecture variation. We compute equivalent plots to Figure 1 for high and low price series, respectively, which are indistinguishable from those for the mean price series presented.

(ii) Our previous analysis of price convergence to the macro-regional average may provide distorted results given that there are substantial differences between 'core' and 'periphery' prefectures within each macroregion. ${ }^{48} \mathrm{We}$ analyzed convergence of the 'periphery' prefectures to the 'core' average price as well as price convergence in a reduced sample made up only

\footnotetext{
${ }^{47}$ The millet price series are available for 72 prefectures of the North and we have $1^{\text {st }}$ and $3^{\text {rd }}$ grade rice prices for 110 and 108 Southern prefectures, respectively. We further directly compared the convergence speeds for $1^{\text {st }}$ and $3^{\text {rd }}$ grade rice price series: given the higher value-to-weight ratio of the former one would also expect it to have a higher speed of convergence. This is indeed the case in our sample.

${ }^{48}$ For our analysis of convergence to the provincial mean price (see online Appendix) we followed the spirit of Goldberg and Verboven (2005) to compute the relative price ratio using the price for the prefecture hosting the provincial capital (instead of the provincial mean) as the reference price. Results again closely follow the patterns described above.
} 
of 'core' prefectures which represent the more advanced/commercialized parts of the country. Results are again in line with those reported.

Motivated by the suggestion in Wang (1989: 445-6) and elsewhere that Suzhou in Jiangsu province was the center of a single integrated rice market covering the macro-regions of Central and Southern China we also compute the relative price ratio taking the Suzhou prefecture price as reference price. We find this yields statistically identical results to adopting the regional mean as reference price. We further investigated the case of Lingnan (Guangxi and Guangdong) in South China, analyzing convergence to the macro-region average and to Guangzhou, respectively, with results qualitatively identical to those in the larger samples discussed above. ${ }^{49}$

Although wheat was not the staple crop in South China (Marks, 1998), the availability of wheat prices in the South enables us to investigate price convergence in 156 prefectures of North and South China. Convergence analysis in a 20-year rolling window shows identical patterns to those described above.

(iii) Our empirical analysis assumes that prices either diverge (i.e. relative prices follow a unit root process) or that they converge in a linear fashion. The seminal contribution by Taylor (2001) has highlighted that a violation of this linearity assumption can lead to significant bias in the estimated convergence parameter and thus the implied half-life. ${ }^{50} \mathrm{We}$ adopt a procedure developed for the panel by Cerrato, de Peretti, Larsson, and Sarantis (2011) which tests the relative price series under the null of a unit root but allows for a nonlinear stationary process under the alternative, while at the same time accounting for cross-section dependence. These tests suggest that from around 1790 onwards we can no longer reject the null of nonstationary

\footnotetext{
${ }^{49}$ Analysis by macro-region and by province provided the same finding, as did a North China sample excluding Zhili province, which may be argued to have had distorted grain markets due to the sale of tribute grain by Eighth Banner soldiers (Cheung, 2008).

${ }^{50}$ Taylor (2001) motivates the concern over nonlinear convergence by suggesting a 'band of inaction' whereby the relative price behaves like a random walk (nonstationary) process inside a certain interval and like a mean-reverting (stationary) process if it strays outside these bounds. We provide further details and illustrations in an online Appendix.
} 
relative prices in either our North or South China samples: from this date onwards grain markets in North and South China were thus fragmented.

(iv) Does our empirical approach capture sufficient unobserved heterogeneity? Following Pesaran, Smith, and Yamagata (2013), we add the cross-section averages of prefectural wheat prices (in lagged levels and first differences according to the lag structure of the specification) to the crosssection averages for the rice prices in convergence regression models for 76 Southern Chinese prefectures where these data are available: the common shocks and network effects driving rice prices in the South are likely also to affect wheat prices in the same prefectures, and the methodology applied here exploits this commonality to allow us to potentially improve our estimates for rice price convergence by constructing improved proxies for the unobserved factors. The (CCE) Mean Group estimates for this specification confirm the secular decline in the average level of Southern market integration. ${ }^{51}$

These and other results are based on using cross-section averages within Skinner (1977a) macro-regions to capture cross-section dependence. When we alternatively use Buck's (1937) agro-climatic regions or the entire sample of prefectures in the South or North to construct the cross-section averages our findings are qualitatively unchanged.

\section{Concluding Remarks}

In this paper we analysed the extent and dynamics of market integration and disintegration during the 'Golden Age' of the Qing Dynasty, and contrasted our findings with those from a number of European economies as well as a cross-European sample of markets. Our empirical results challenge the conventional wisdom developed in the recent literature of Chinese market efficiency on the eve of the Industrial Revolution (Shiue and Keller, 2007).

\footnotetext{
${ }^{51}$ We also followed the suggestion in Chudik and Pesaran (2015) to investigate the inclusion of further lags of the cross-section averages to the model along with a bias-correction in form of a half-panel jackknife. Results for six additional lags (following the rule of thumb suggested by these authors) provide clear evidence for secular decline in market integration in South and North China in line with our previous findings.
} 
While we use the same data for Qing China as these authors, albeit for an extended time period (their data ends in 1795) and an expanded geographical area (we separately analyze wheat prices in a sample of Northern prefectures), our results are fundamentally different for two important reasons: first, our empirical analysis of price convergence accounts for the impact of common shocks and the network effect of trade. Second, we allow for market integration to evolve over time by shifting the analysis from the full time series of almost 800 monthly observations to shorter time windows.

Our price convergence analysis establishes that secular market disintegration occurred in both Northern and Southern Chinese regions. While levels of integration in China were comparable to those of Western Europe in the 1750 s, by the end of the $18^{\text {th }}$ century a very substantial gap had opened up and the Great Divergence was well and truly under way. ${ }^{52}$

The present study focuses on the macro-economic evolution of market integration employing a simple model for price behavior in a general equilibrium framework, which recognizes that trade, and thus price behavior, is subject to network effects and common shocks. While we carried out a number of robustness checks which suggest that the process of secular market disintegration we uncover was pervasive - from the North China macro-region to that of Lingnan in the far South to that of the highly commercialized Lower Yangzi region in the East - our analysis does not uncover what the patterns of disintegration looked like within these units of analysis: How did integration fare within geomorphological or political boundaries as compared with across

\footnotetext{
${ }^{52}$ Studer (2015) and others have suggested that markets in China and Europe were fragmented in the early modern period - hence, he argues, Shiue and Keller's (2007) finding of similar levels of integration between the two continents - and that a gradual process of integration in Europe did not gain speed until the arrival of the steam engine during the $19^{\text {th }}$ century. Our analysis of Belgian, English, French and German national samples as well as a cross-European sample finds uniformly high levels of market integration throughout the $18^{\text {th }}$ and early $19^{\text {th }}$ centuries. Although our analysis of European economies focuses on the average level of integration in each sample and thus hides underlying heterogeneity to some extent it is not the case that this heterogeneity will cause any bias in our estimates. Since our focus in this paper is on the macro-level of market integration we leave further investigation of the European data along the lines of the macro-region analysis for China in Figure 2(b) for future work.
} 
these units? Did 'peripheral' prefectures drop out of the network of integration first? In a companion paper we shift the focus to the micro-economic experience of market dynamics to answer these questions whilst still accounting for trade network effects and common shocks. This also enables us to chart some of the narrative in the rich literature on social and economic history of Qing China which had to be left by the wayside in the present study.

\section{Acknowledgements}

We thank Steven Block, Shuo Chen, Giovanni Federico, James Fenske, Christopher Gilbert, Sourafel Girma, David Harvey, Keith Head, Wolfgang Keller, Nan Li, Cong Liu, Mary Lovely, Debin Ma, Kaixiang Peng and Kevin O'Rourke for helpful comments and suggestions. Seminar and conference participants at the 2013 GEP conference in Ningbo; 2013 ETSG meeting in Birmingham; Birmingham University; Nankai University; the 2015 CES North America Conference at Michigan University; Nottingham University; the 2015 Xiamen Young Economist Society conference; George Mason University; the 2015 CSAE conference in Oxford; the $3^{\text {rd }}$ Xiamen University International Workshop on Economic Analysis of Institutions; and the $3^{\text {rd }}$ Workshop in Empirical Economic History at Peking University provided useful feedback on earlier drafts of the paper. We are grateful to Edmund Cannon and Liam Brunt for kindly providing a revised version of their English Corn Returns data. Thanks are also due to Gerdie Everaert and especially Sandy Van Laer for their help with securing the Belgian data. The usual disclaimers apply.

\section{Online Appendix}

A detailed online Appendix is available at http://tinyurl.com/qyqzj96 or http://www.nottingham.ac.uk/gep/news-events/news/papers/1512.aspx 


\section{Sources (Price data)}

Chinese grain prices

Qing dai liangjia ziliao ku [Qing Dynasty Grain Price Database]. Institute of Modern History, Academia Sinica, Taiwan. Available online at:

http://mhdb.mh.sinica.edu.tw/foodprice.

English wheat prices

Cannon, Edmund and Liam Brunt (2004). Weekly British Grain Prices from the London Gazette, 1770-1820 [computer file]. Colchester, Essex: UK Data Archive [distributor], July 2004. SN: 4383. Available online at:

http://dx.doi.org/10.5255/UKDA-SN-4383-1.

Belgian wheat prices

Vandenbroecke, Chris (1973). 'Het prijsonderzoek van de regering voor de steden van de Oostenrijkse Nederlanden voor graangewassen, vlas en garen (1765-1794)', in C. Verlinden (ed.) Dokumenten voor de geschiedenis van prijzen en lonen in Vlaanderen en Brabant (XIIIe-XIXe eeuw) Vol. IV. Bruges: De Tempel, pp. 1-49. Available online in due course.

French wheat prices

Labrousse, Ernest, Ruggiero Romano and F.-G. Dreyfus (1970). Le Prix du froment en France au temps de la monnaie stable 1726-1913. Paris: S.E.V.P.E.N. Available online in due course.

German rye prices

Rahlf, Thomas, (1996 [2005]) Getreidepreise in Deutschland 1500-1800 [computer file]. GESIS (Leibniz Institut für Sozialforschung) Datenarchiv, Köln. histat. Studiennummer 8140. Datenfile Version 1.0.0. Available online at: $\underline{w w w . g e s i s . o r g / h i s t a t . ~}$

European wheat prices

Allen, Bob and Richard Unger (accessed July 2015) Global Commodity Prices

Database. Available online at: $\underline{w w w . g c p d b . i n f o}$. 


\section{References}

Andrews, Donald W. (2005). "Cross-section Regression with Common Shocks." Econometrica, 73(5): 1551-85.

Anselin, Luc. 1988. Spatial econometrics: methods and models. Dordrecht: Kluwer Academic.

Bai, Jushan and Serena Ng, 2002. "Determining the Number of Factors in Approximate Factor Models.” Econometrica, 70(1): 191-221.

Bailey, Natalia, Sean Holly, and M. Hashem Pesaran. 2015. "A two stage approach to spatiotemporal analysis with strong and weak cross-sectional dependence." Journal of Applied Econometrics, forthcoming.

Bailey, Natalia, George Kapetanios, and M. Hashem Pesaran. 2015. "Exponent of Cross-Sectional Dependence: Estimation and Inference." Journal of Applied Econometrics, forthcoming.

Berg, Kimberly A. and Nelson C. Mark. 2015. "Third-country effects on the exchange rate." Journal of International Economics, 96(2): 227-43.

Brenner, Robert, and Christopher Isett. 2002. "England's divergence from China's Yangzi Delta: Property relations, microeconomics, and patterns of development." The Journal of Asian Studies, 61(2): 609-62.

Bernard, Andrew B. and Charles I. Jones. 1996. "Productivity across Industries and Countries: Time Series Theory and Evidence." Review of Economics and Statistics, 78(1): 135-46.

Brunt, Liam and Edmund Cannon. 2013. "The truth, the whole truth and nothing but the truth: the English Corn Returns as a data source in economic history, 1770-1914.” European Review of Economic History 17(3): 318-339.

Brunt, Liam and Edmund Cannon. 2014. "Measuring market integration in the English wheat market, 1770-1820: New methods, new answers." Explorations in Economic History 52: 111-130. 
Buck, John Lossing. 1937. Land Utilization in China: A Study of 16786 Farmers in 168 Localities and 38256 Farm Families in Twenty Two Provinces in China, 1929-1933. University of Chicago Press.

Buyst, Erik, Stefan Dercon, and Bjorn van Campenhout. 2006. "Road Expansion and Market Integration in the Austrian Low Countries during the Second Half of the $18^{\text {th }}$ Century." Histoire \& Mesure 21(1):185-219.

Cheung, Sui-Wai. 2008. The Price of Rice: Market Integration in EighteenthCentury China. Bellingham: Western Washington University Press.

Chuan, Han-sheng, and Richard A. Kraus. 1975. Mid-Ch'ing Rice Markets and Trade: An Essay in Price History. Harvard University Press.

Chudik, Alexander, and M. Hashem Pesaran 2013. "Large panel data models with cross-sectional dependence: a survey." CESifo Working Paper No. 4371.

Chudik, Alexander, and M. Hashem Pesaran 2015. "Common correlated effects estimation of heterogeneous dynamic panel data models with weakly exogenous regressors." Journal of Econometrics, 188(2): 393-420.

Cliff, Andrew David, and J. Keith Ord. 1973. Spatial autocorrelation. London: Pion.

Coakley, Jerry, Ana-Maria Fuertes, and Ron P. Smith. 2006. "Unobserved heterogeneity in panel time series models." Computational Statistics \& Data Analysis, 50(9): 2361-80.

Crucini, Mario J., and Mototsugu Shintani. 2008. "Persistence in law of one price deviations: Evidence from micro-data." Journal of Monetary Economics 55: 629-44.

Daudin, Guillaume. 2010. "Domestic Trade and Market Size in LateEighteenth-Century France.” Journal of Economic History 70(3): 716-43.

Deaton, Angus, and Guy Laroque. 1992. "On the Behavior of Commodity Prices." Review of Economic Studies, 59: 1-24. 
Deaton, Angus, and Guy Laroque. 1996. "Competitive Storage and Commodity Price Dynamics.” Journal of Political Economy, 104(5): 896923.

Eastman, Lloyd E. 1988. Family, Fields and Ancestors: Constancy and Change in China's Social and Economic History, 1550-1949. Oxford University Press.

Eberhardt, Markus, Christian Helmers, and Hubert Strauss. 2013. "Do spillovers matter when estimating private returns to $\mathrm{R} \& \mathrm{D}$ ? Review of Economics and Statistics 95(2): 436-48.

Eberhardt, Markus, and Andrea Presbitero. 2015. "Public debt and growth: Heterogeneity and non-linearity". Journal of International Economics, 97(1): 45-58.

Elvin, Mark. 1973. The pattern of the Chinese past: A social and economic interpretation. Stanford University Press.

Elvin, Mark. 2004. The Retreat of the Elephants: An Environmental History of China. Yale University Press.

Fackler, Paul L., and Barry K. Goodwin. 2001. "Spatial Price Analysis." In: G. Gardner and G.Rausser (eds) Handbook of Agricultural Economics Vol. 1, Elsevier.

Fan, C. Simon, and Xiaogdong Wei. 2006. "The Law of One Price: Evidence from the Transitional Economy of China." Review of Economics and Statistics, 88(4): 682-97.

Fairbank, John K. and Merle Goldstein. 2006. China: A new history. Belknap Press of Harvard University Press, $2^{\text {nd }}$ edition.

Frank, Andre Gunder. 1998. ReOrient: Global Economy in the Asian Age. Berkeley: University of California Press.

Geweke, John. 1977. "The dynamic factor analysis of economic time series models.” In J. Aigner \& A.S. Goldberger (eds) Latent Variables in SocioEconomic Models. Amsterdam: North-Holland, pp.365-83. 
Goldberg, Pinelopi K. and Frank Verboven. 2005. "Market Integration and Convergence to the Law of One Price: Evidence from the European car Market." Journal of International Economics, 65(1): 49-73.

Hamilton, Lawrence C. 1992. "How Robust is Robust Regression?" Stata Technical Bulletin, 1(2).

Head, Keith, and Thierry Mayer. 2014. "Gravity equations: Workhorse, toolkit, and cookbook." In: Gita Gopinath, Elhanan Helpman, and Kenneth Rogoff (eds) Handbook of International Economics, Vol. 4. Amsterdam: Elsevier North-Holland.

Huang, Philip C.C. 2002. "Development or involution in $18^{\text {th }}$ century Britain and China?" The Journal of Asian Studies, 61(2): 501-38.

Jia, Ruixue. 2014. "Weather Shocks, Sweet Potatoes and Peasant Revolts in Historical China.” Economic Journal, 124(575): 92-118.

Juselius, Katarina. 2006. The Cointegrated VAR Model: Methodology and Applications. Oxford University Press.

Kapetanios, George, M. Hashem Pesaran, and Takashi Yamagata. 2011. "Panels with Nonstationary Multifactor Error Structures." Journal of Econometrics, 160(2): 326-348.

Keller, Wolfgang, and Carol H. Shiue. 2015. "Market Integration as a Mechanism of Growth”. Unpublished working paper, March.

Kim, Nanny. 2008. "Transport im China der spaeten Kaiserzeit, 1500-1900: Eine Bestandsaufnahme.” In: Stieferle, Rolf Peter (Ed) Transportgeschichte. Berlin.

Li, Lillian M. 2000. "Integration and Disintegration in North China's Grain Markets, 1738-1911." Journal of Economic History, 60(3): 665-99.

Li, Lillian M. 2007. Fighting famine in North China: state, market, and environmental decline, 1690s-1990s. Stanford University Press.

Li, Lillian M., and Alison Dray-Novey. 1999. "Guarding Beijing's food security in the Qing dynasty: state, market, and police." Journal of Asian Studies, 58(4): 992-1032. 
Li, Rongsheng. 2009. “Qingdai (1645-1911) Meinian Liuru Zhongguo Baiyin Shuliang de Chubu Guji [Estimating the Annual Amount of Silver Inflow during the Qing Dynasty in China (1645-1911)]." Renwen ji Shehui Kexue Qikan [Journal of Humanities and Social Sciences], 5(2): 31-58.

Marks, Robert B. 1991. "Rice Prices, Food Supply, and Market Structure in Eighteenth-Century South China." Late Imperial China, 12(2): 64-116

Marks, Robert B. 1998. Tigers, Rice, Silk, and Silt: Environment and Economy in Late Imperial South China. Cambridge University Press.

Moran, Patrick. 1948. "The interpretation of statistical maps." Journal of the Royal Statistical Society, Series B, 10(2): 243-51.

Perkins, Dwight H. 1969. Agricultural development in China, 1368-1968. Edinburgh University Press.

Pesaran, M. Hashem. 2006. "Estimation and inference in large heterogeneous panels with cross-section dependence." Econometrica, 74(4): 967-1012.

Pesaran, M. Hashem. 2015. "Testing weak cross-sectional dependence in large panels." Econometric Reviews, 34(6-10): 1088-1116.

Pesaran, M. Hashem and Ron P. Smith. 1995. "Estimating long-run relationships from dynamic heterogenous panels." Journal of Econometrics, 68(1): 79-113.

Pesaran, M. Hashem, L. Vanessa Smith and Takashi Yamagata. 2013. "Panel Unit Root Tests in the Presence of a Multifactor Error Structure." Journal of Econometrics, 175(2): 94-115.

Pesaran, M. Hashem, and Elisa Tosetti. 2011. "Large panels with common factors and spatial correlation." Journal of Econometrics, 161(2): 182202.

Phillips, Peter C.B., and Donggyu Sul. 2007. "Bias in dynamic panel estimation with fixed effects, incidental trends and cross section dependence." Journal of Econometrics, 137(1): 162-88. 
Pomeranz, Kenneth. 2000. The Great Divergence: China, Europe, and the Making of the Modern World Economy. Princeton University Press.

Rawski, Evelyn S. 1972. Agricultural Change and the Peasant. Cambridge, MA: Harvard University Press.

Rowe, William T. 2011. "Introduction: The Significance of the QianlongJiaqing Transition in Qing History." Late Imperial China, 32(2): 74-88.

Sarafidis, Vasilis, and Tom Wansbeek. 2012. "Cross-sectional dependence in panel data analysis." Econometric Reviews, 31(5): 483-531.

Sargent, Thomas J., and Christopher A. Sims. 1977. "Business cycle modeling without pretending to have too much a priori economic theory." In: Christopher Sims (ed) New methods in business cycle research, pp. 145-68. Federal Reserve Bank of Minneapolis.

Shiue, Carol H. 2002. "Transport Costs and the Geography of Arbitrage in Eighteenth Century China." American Economic Review, 92(5): 1406-19.

Shiue, Carol H. 2004. "Local Granaries and Central Government Disaster Relief, Moral Hazard and Intergovernmental Finance in $18^{\text {th }}$ and $19^{\text {th }}$ Century China." Journal of Economic History, 64(1): 100-24.

Shiue, Carol H. 2015. "The organization and scope of grain markets in Qing China, 1644-1911.” In: R.J. van der Spek, Bas van Leeuwen and Jan Luiten van Zanden (eds) A History of Market Performance From Ancient Babylonia to the modern world. Chapter 13: 339-359. London: Routledge.

Shiue, Carol H., and Wolfgang Keller. 2007. "Markets in China and Europe on the Eve of the Industrial Revolution." American Economic Review, 97(4): 1189-1216.

Skinner, G. William. 1977a. "Regional urbanization in nineteenth-century China." In Skinner, G. William (ed.) The City in Late Imperial China. Part one, 211-49. Stanford University Press.

Skinner, G. William. 1977b. "Cities and the Hierarchy of Local Systems." In Skinner, G. William (ed.) The City in Late Imperial China. Part two, 275351. Stanford University Press. 
Sng, Tuan Hwee. 2014. "Size and Dynastic Decline: The Principal-Agent Problem in Late Imperial China 1700-185." Explorations in Economic History, 54: 107-27.

Studer, Roman. 2015. The Great Divergence Reconsidered: Europe, India, and the Rise to Global Economic Power. Cambridge University Press.

Taylor, Alan M. 2001. "Potential Pitfalls for the Purchasing-Power-Parity Puzzle? Sampling and Specification Biases in Mean-Reversion Tests of the Law of One Price." Econometrica 69(2): 473-98.

Vries, Peer. 2015. State, Economy and the Great Divergence: Great Britain and China, 1680s-1850s. London: Bloomsbury.

Wang, Yeh-Chien. 1989. "Food Supply and Grain Prices in the Yangzi Delta in the Eighteenth Century." In Yung-san Lee and Ts'iu-jung Liu (eds) China's Market Economy in Transition. Taipei: Institute of Economics, Academia Sinica.

Wang, Yeh-Chien. 1992. "The Secular Trend of Rice Prices in the Yangzi Delta, 1638-1935”, In Thomas G. Rawski and Lillian M. Li (eds) Chinese History in Economic Perspective, pp.35-68. Berkeley and Los Angeles: University of California Press.

Wang, Yeh-Chien, and Zen-yi Chen. 2002. "Grain Markets in Eighteenthcentury China". In Ts'ui-jung Liu and Shou-chien Shih (eds) Economic History, Urban Culture and Material Culture. Nankang, Taibei: Academia Sinica. Reprinted in Wang Yeh-Jien, Collected Essays in the Economic History of Qing China, Vol. 3, pp. 397-415. Taipei: Daoxiang Publisher, 2004).

Watson, Andrew. 1972. Transport in transition: The evolution of traditional shipping in China. Ann Arbor: University of Michigan Press.

Westerlund, Joakim, and Jean-Pierre Urbain. 2015. "Cross-sectional averages versus principal components.” Journal of Econometrics, 185(2): $372-7$. 
Whittle, Peter. 1954. "On stationary processes in the plane." Biometrika, 41(3/4): 434-49.

Wiens, Herold J. 1955. "Riverine and Costal Junks in China's Commerce", Economic Geography, 31(3): 248-64.

Will, Pierre-Etienne, and Roy Bin Wong. 1991. Nourish the people: the state civilian granary system in China, 1650-1850. Ann Arbor: University of Michigan Press.

Wong, Roy Bin. 1997. China transformed: historical change and the limits of European experience. Ithaka, New York: Cornell University Press. 


\section{Figures}

Figure 1: Regional and Macro-Regional Convergence in China
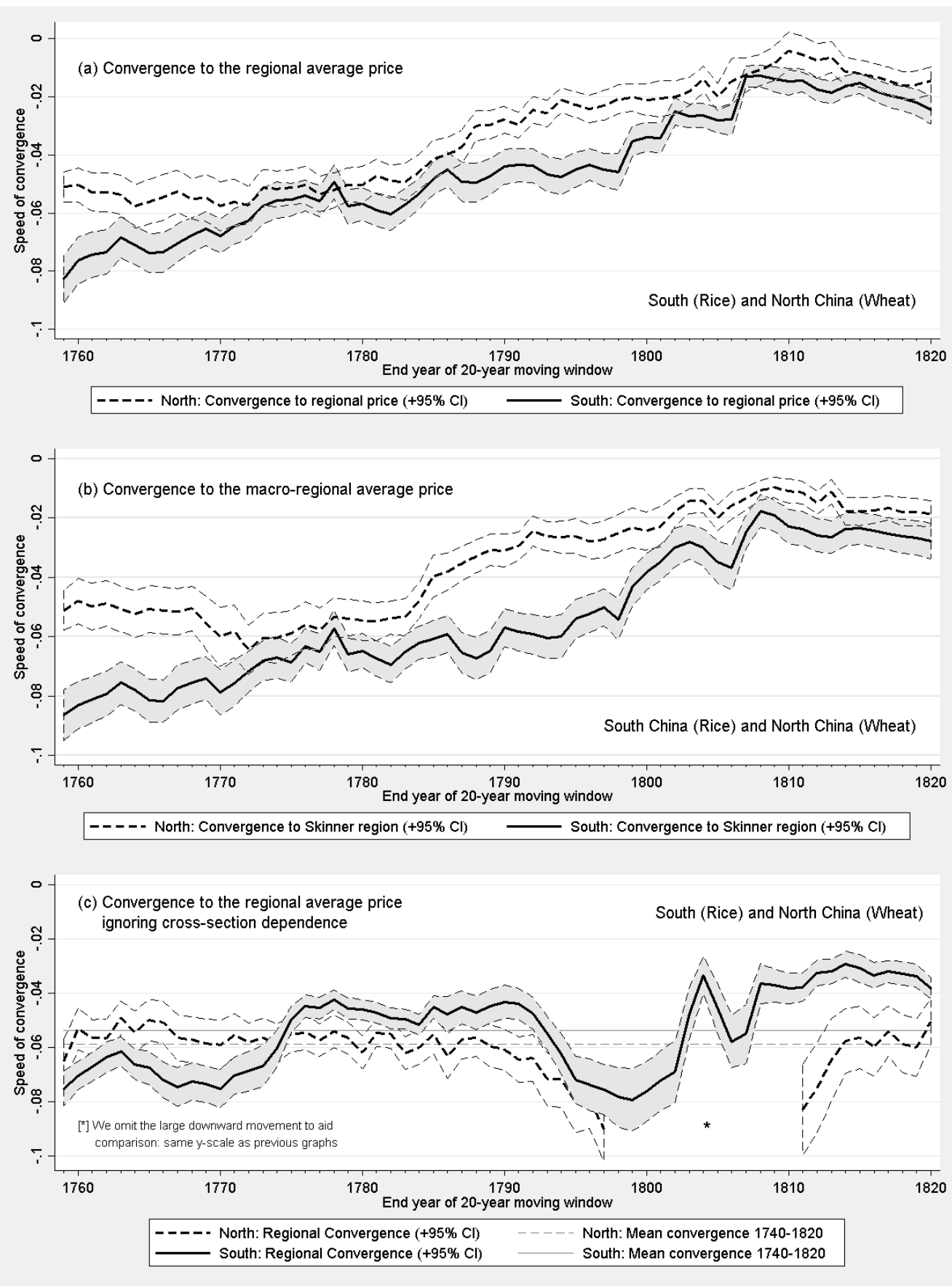

Notes: We plot average convergence coefficients (and their $95 \%$ confidence intervals) from the analysis of Southern (solid line) and Northern Chinese (dashed line) grain prices in 131 and 78 prefectures, respectively, using a 20 -year rolling window. 
Figure 2: Comparison of Chinese and European Grain Price Convergence
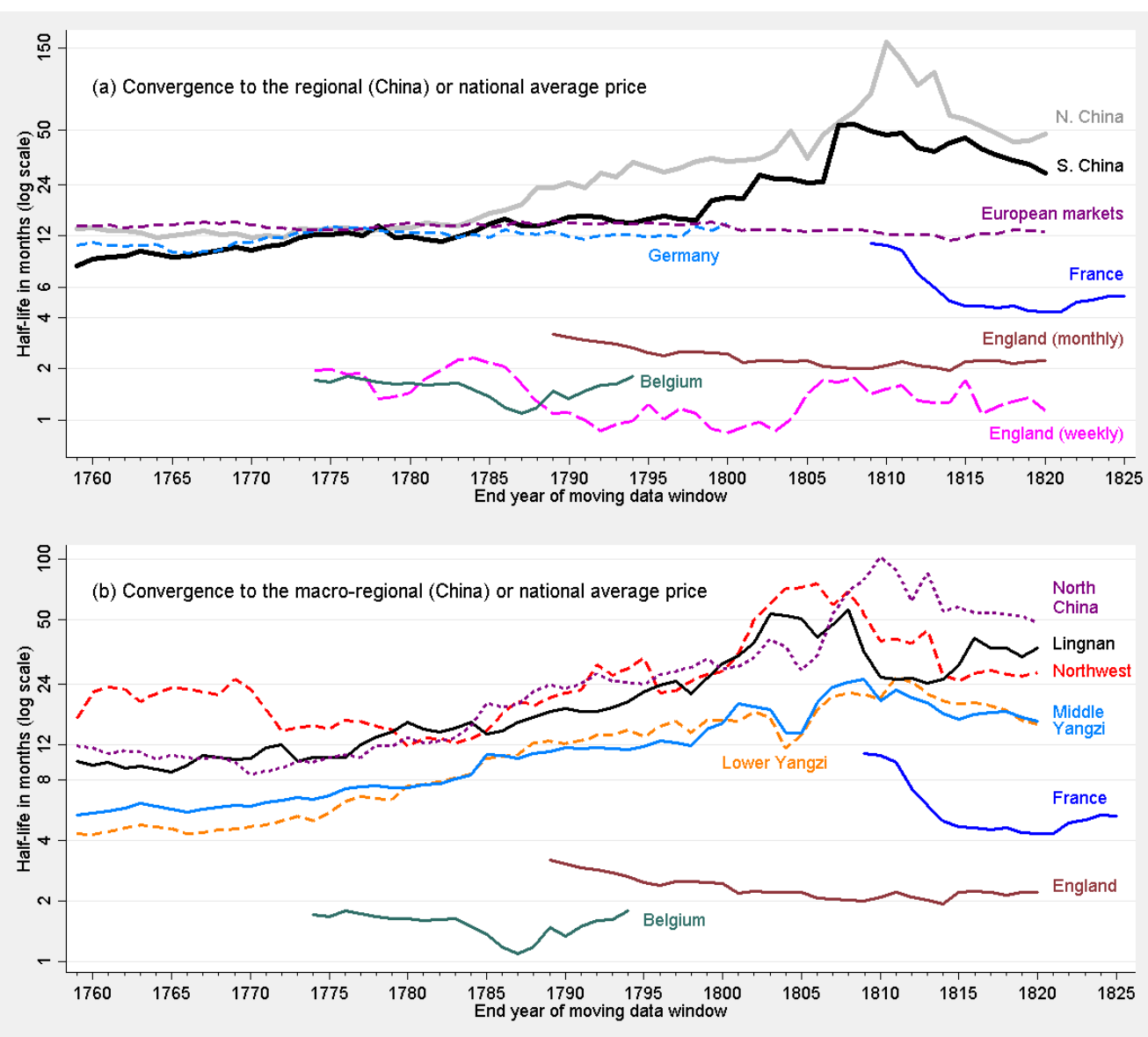

Notes: We plot the half-lives (in months) implied by the robust mean convergence estimates from the analysis of various samples comparing Chinese regions (in graph (a): North and South China, in graph (b): selected macro-regions) and European market integration (note that the $y$-axis is on a logarithmic scale and that for illustrative purposes the scales differ between the two graphs). We omit confidence intervals to aid illustration. The longer the half-life, the slower is price convergence to the equilibrium. Results for Belgium, England, European markets, France, and North China (both the region in graph (a) and the identically-named Skinner macro-region in graph (b)) are derived from wheat prices, those for South China (and all Southern macro-regions) are for rice and the German results are for rye. Data for Belgium, England, France, and China are monthly, German and European market price series are annual; we also include results for the English county series at the original weekly frequency. Graph (b) exclusively uses data available at monthly frequency. Results are derived from rolling windows of 60 (annual German and European data), 20 (Chinese and English monthly data), 10 (French and Belgian monthly data) and 5 (weekly English county data) years' length. For illustrative purposes we exclude convergence plots for the Upper Yangzi and the Southeast Coast macro-regions in graph (b) - these are available in the online Appendix. We only have data for Guizhou province within the Yungui macro-region, so that this macroregion is also excluded. A price convergence plot for Guizhou province is contained in the online Appendix. 